Plant Tissue Cult. \& Biotech. 23(1): 79-85, 2013 (June)

$\overline{\text { PTC\&B }}$

\title{
In vitro Regeneration of an Endangered Medicinal Plant Withania somnifera using Four Different Explants
}

\author{
A. Arumugam* and K. Gopinath \\ Division of Bio-Nanotechnology, Department of Nanoscience \& Technology, Alagappa \\ University, Karaikudi-630 004, Tamilnadu, India \\ Key words: Withania somnifera, Leaf callus, Cotyledons, Hypocotyls, Epicotyls
}

\begin{abstract}
An efficient protocol was developed for highly regenerative capacity from leaf explant of Withania somnifera (L.) Dunal - an endangered medicinal plant. Calli were regenerated from four different explants like leaves, cotyledons, hypocotyls and epicotyls. MS supplemented with different concentrations of 2,4-D, BAP and NAA were used. The calli $(94.33 \pm 1.20 \%)$ were obtained from the leaf explant in 2,4-D $3.0 \mathrm{mg} / \mathrm{l}$. The highest number of multiple shoots $(85.67 \pm 0.88 \%)$ were obtained from the leaf callus at $4.0 \mathrm{mg} / \mathrm{l}$ BAP. Shootlets forming calli were transferred to the rooting medium containing $10.0 \mathrm{mg} / \mathrm{l}$ NAA to produce multiple roots $(89.33 \pm 0.88 \%)$. The regenerated rooted shootlets were transferred to small polythene bags, which contain a sterilized cow-dung, sand and red soil $(1: 2: 3)$ and kept in a mist house. After acclimation in the mist house the regenerated plantlets were hardened in the greenhouse and transferred to soil, which showed $85 \%$ survival rate. This new protocol was standardized for easy mass propagation of $W$. somnifera using leaf explant.
\end{abstract}

\section{Introduction}

Withania somnifera (L.) Dunal, a member of Solanaceae is widely used in the treatment of inflammatory, anti-tumour agent (Chopra et al. 1958). Is short shrub, growing to a height of $30-150 \mathrm{~cm}$, greyish-yellow long rhizomes. It is well-known for years as an important drug in Ayurvedic literature. Root of the Withania somnifera (Ashwagandha) plant reportedly exhibit antioxidant, immunomodulatory and haematopoietic properties (Mishra et al. 2000).

Ashwagandha leaves, roots and seeds are used in Ayurveda and Unani system of medicines. Roots were prescribed as medicines for hiccups, several female disorders, bronchitis, rheumatism, dropsy, stomach and lung inflammation, and skin diseases. It is also one of the ingredient in medicines prescribed for

*Author for correspondence: <sixmuga@yahoo.com>. 
curing disability and sexual weakness in males (Joshi et al. 2010). According to Red data book of threatened species, 44 plant species are critically endangered, 113 endangered and 87 vulnerable. W. somnifera proved to be $99.75 \%$ of the endangered medicinal plant (Siddique et al. 2005, Rahman 2001). Active pharmacological components of Withania somnifera constituents with withanolides (Steroidal lactones with ergostane skeleton) and alkaloids (Elsakka et al. 1990). The active content of Indian Withania somnifera are withaterin-A and withanolide-D, both are present in leaves and roots of the plant which are used as a source of drugs. Total alkaloid content in the root of the Indian type has been reported to be between 0.13 and $0.31 \%$ of this plant which showed antitumor and radio sensitizing effects in animal models (Sharma et al. 2009). It also possesses anti-stress, immunomodulatory, antioxidant and anti-bacterial activity (Kupchan et al. 1965, Uma et al. 1992, 1993).

Due to the medicinal value, these plants were collected and used as raw material in medicinal industry at a large scale, leading to over exploitation and it becomes an endangered plant species. One of major the problems for commercial cultivation, $W$. somnifera seed viability very poor. It takes long of time for uniform strains and better growth and productivity. Micropropagation of $W$. somnifera using different explants such as shoot tips (Sen and Sharma 1991), auxiliary meristems (Roja and Heble 1991) auxiliary leaves, auxiliary shoot and hypocotyl and root segments (Rani and Grover 1999) has been demonstrated. Seed viability was limited to more than one year (Roja and Heble 1991). The callus formation from auxiliary meristem in MS with $2 \mathrm{mg} / \mathrm{l}$ 2,4-D, (Baburaj and Gunasekaran 1995).

The present investigation was carried out to develop a simple and efficient protocol for rapid micropropagation of $W$. somnifera by using leaf explant. This is an alternative and cost effective method to improve the crop production of an endangered medicinal plant.

\section{Materials and Methods}

Withania somnifera L. Dunal explants and seeds were collected from the Irula Tribe Women's Welfare Society (ITWWS) - Kanchipuram, Tamil Nadu, India. The explants of auxiliary leaves $1-2 \mathrm{~cm}$, segments were taken from $4-5$ months old plants while hypocotyl, cotyledon and epicotyl segments of $0.5-1 \mathrm{~cm}$ size explants were removed from 10 - 15 days old seedling. All the explants were washed thoroughly with running tap water for $20 \mathrm{~min}$, then they were cleaned with liquid detergent Tween $20(1 \% \mathrm{v} / \mathrm{v})$ for 5 - $10 \mathrm{~min}$ and rinsed with sterile double distilled water. They were then surface sterilized with $0.01 \% \mathrm{HgCl}_{2}$ (w/v) 
solution for $2 \mathrm{~min}$ and again washed well in distilled water three - four times to remove all traces of $\mathrm{HgCl}_{2}$. Surface sterilized explants were aseptically inoculated in MS with $30 \%$ sucrose and solidified with $0.8 \%$ agar. The MS with different concentrations of 2, 4-D (0.1 - $20.0 \mathrm{mg} / \mathrm{l})$, NAA $(0.1-20.0 \mathrm{mg} / \mathrm{l})$ and BAP $(0.1-20$ $\mathrm{mg} / \mathrm{l})$ were used. $\mathrm{pH}$ was adjusted to $5.8 \pm 0.1$ with $0.1 \mathrm{~N} \mathrm{NaOH}$ or $0.1 \mathrm{~N} \mathrm{HCl}$ before autoclaving at $121^{\circ} \mathrm{C}$ and $15 \mathrm{lb}$ for $20 \mathrm{~min}$. All cultures were maintained at $22 \pm 1^{\circ} \mathrm{C}$ under $16 \mathrm{hrs}$ photoperiod at a photosynthetic flux of $12.6 \mu \mathrm{mol} / \mathrm{m}^{2} / \mathrm{s}$, which was provided by cool daylight fluorescent lamps. For hardening-off, 7 to 8 weeks old rooted shootlets were removed from the culture flacks. After freeing the agar with the running water they were transferred into small polythene bags containing sterilized cow-dung, sand and red soil $(1: 2: 3)$ and kept in a mist house. After acclimation in the mist house for 2 months, they were transferred to greenhouse.

\section{Results and Discussion}

Four different explants of Withania somnifera were used at different concentrations of 2, 4-D in MS for callus initiation. At 0.1 to $1.0 \mathrm{mg} / \mathrm{l}$ 2,4-D in MS produced minimum number of callus as against maximum number at the concentration of $1.5-4.0 \mathrm{mg} / \mathrm{l}$ 2,4-D. Callus initiation was totally reduced by increasing the concentration of 2,4-D $20 \mathrm{mg} / \mathrm{l}$ in MS. The overall callus induction frequency on MS varied from $44.67 \pm 1.45$ to $94.33 \pm 1.20 \%$ in leaf explants (Table 1 ), while in hypocotyl, epicotyl and cotyledon the frequency ranged from $32.00 \pm$ 1.15 to $80.00 \pm 0.58,36.67 \pm 0.88$ to $84.00 \pm 1.00$ and $25.00 \pm 1.15$ to $89.00 \pm 0.5832-$ $80 \%$, respectively (Fig. 1A-C). Similarly, the maximum number of calli were obtained from leaf explant of $W$. somnifera at 2,4-D (2 mg/l) and $\mathrm{Kn}(0.2 \mathrm{mg} / \mathrm{l})$ (Rani and Grover 1999).

All the in vitro regenerated calli were transferred to MS with different concentrations of BAP $(0.1-20 \mathrm{mg} / \mathrm{l})$. The maximum number of greenish shoots were produced at the concentration of BAP $(2.0-4.0 \mathrm{mg} / \mathrm{l})$. Shoot initiation was reduced, by increasing the concentration of BAP $(10-20 \mathrm{mg} / \mathrm{l})$ on MS. The overall callus induction frequency on MS varied from $5.33 \pm 0.33$ to $85.67 \pm 0.88 \%$ with leaf explant (Table 2), while in hypocotyl, epicotyl and cotyledon the frequency ranged from $23.00 \pm 1.00$ to $80.67 \pm 0.88,8.00 \pm 1.00$ to $52.00 \pm 1.15$, and $6 . .00 \pm 2.00$ to $19.00 \pm 0.58 \%$, respectively (Fig. 1D).

Leaf, cotyledon, hypocotyl and epicotyl explants derived from shootlets were transferred to root initiation MS containing different concentrations of NAA (0.1 - $20 \mathrm{mg} / \mathrm{l})$. There was no significant effect of root induction in shootlets at the low 
Table1. Effect of different concentrations of 2,4-D for callus induction on different explants of Withania somnifera.

\begin{tabular}{ccccc}
\hline \multirow{2}{*}{$\begin{array}{c}\text { MS+ 2,4-D } \\
(\mathrm{mg} / \mathrm{l})\end{array}$} & \multicolumn{4}{c}{ Callus initiation $(\%)$ mean $\pm \mathrm{SE}$} \\
\cline { 2 - 5 } & $\mathrm{L}$ & $\mathrm{C}$ & $\mathrm{H}$ & $\mathrm{E}$ \\
\hline 0.1 & $44.67 \pm 1.45$ & $41.67 \pm 1.20$ & $62.00 \pm 1.15$ & $25.00 \pm 1.15$ \\
0.5 & $56.00 \pm 1.15$ & $48.33 \pm 1.20$ & $48.67 \pm 1.45$ & $40.67 \pm 1.45$ \\
1.0 & $70.00 \pm 1.15$ & $44.67 \pm 0.33$ & $61.33 \pm 1.86$ & $45.67 \pm 1.20$ \\
1.5 & $80.67 \pm 1.45$ & $61.00 \pm 0.58$ & $65.00 \pm 1.15$ & $71.67 \pm 1.76$ \\
2.0 & $91.67 \pm 1.20$ & $62.00 \pm 0.58$ & $73.67 \pm 0.88$ & $80.67 \pm 1.45$ \\
3.0 & $\mathbf{9 4 . 3 3} \pm \mathbf{1 . 2 0}$ & $\mathbf{8 0 . 0 0} \pm 0.58$ & $\mathbf{8 4 . 0 0} \pm \mathbf{1 . 0 0}$ & $\mathbf{8 9 . 0 0} \pm 0.58$ \\
4.0 & $81.00 \pm 0.58$ & $64.33 \pm 0.88$ & $63.67 \pm 0.88$ & $87.00 \pm 1.15$ \\
5.0 & $68.00 \pm 1.53$ & $47.33 \pm 1.20$ & $43.00 \pm 1.15$ & $79.67 \pm 0.88$ \\
10.0 & $64.67 \pm 0.88$ & $32.00 \pm 1.15$ & $36.37 \pm 0.88$ & $46.00 \pm 1.15$ \\
20.0 & $00.00 \pm 0.00$ & $00.00 \pm 0.00$ & $00.00 \pm 0.00$ & $00.00 \pm 0.00$ \\
\hline
\end{tabular}

The results are the mean $\pm \mathrm{SE}$ of 3 replicates, $\mathrm{L}=$ Leaf, $\mathrm{C}=$ Cotyledon, $\mathrm{H}=$ Hypocotyl, $\mathrm{E}=$ Epicotyl.

Table 2. Effect of different concentrations of BAP for shoots induction from the different explants derived from callus of Withania somnifera.

\begin{tabular}{ccccc}
\hline $\begin{array}{c}\text { MS+ BAP } \\
(\mathrm{mg} / \mathrm{l})\end{array}$ & \multicolumn{3}{c}{ Shoots initiation $(\%)$ mean \pm SE } \\
& L DC & CDC & HDC & EDC \\
\hline 0.1 & $00.00 \pm 0.00$ & $23.00 \pm 1.00$ & $25.00 \pm 0.58$ & $00.00 \pm 0.00$ \\
0.5 & $21.67 \pm 1.45$ & $65.33 \pm 1.45$ & $26.00 \pm 1.15$ & $00.00 \pm 0.00$ \\
1.0 & $25.00 \pm 1.15$ & $25.00 \pm 1.00$ & $32.00 \pm 1.15$ & $06.00 \pm 2.08$ \\
1.5 & $27.67 \pm 0.88$ & $58.33 \pm 1.20$ & $35.00 \pm 0.58$ & $07.33 \pm 1.76$ \\
2.0 & $34.33 \pm 1.20$ & $65.00 \pm 1.73$ & $\mathbf{5 2 . 0 0} \pm \mathbf{1 . 1 5}$ & $12.00 \pm 1.15$ \\
3.0 & $53.00 \pm 1.53$ & $49.00 \pm 0.58$ & $50.67 \pm 1.76$ & $15.00 \pm 2.31$ \\
4.0 & $\mathbf{8 5 . 6 7} \pm \mathbf{0 . 8 8}$ & $\mathbf{8 0 . 6 7} \pm \mathbf{0 . 8 8}$ & $39.00 \pm 0.58$ & $\mathbf{1 9 . 0 0 \pm 0 . 5 8}$ \\
5.0 & $82.00 \pm 1.15$ & $72.00 \pm 1.15$ & $20.00 \pm 1.15$ & $18.00 \pm 1.15$ \\
10.0 & $16.33 \pm 0.88$ & $50.00 \pm 0.58$ & $12.00 \pm 1.53$ & $14.00 \pm 0.58$ \\
20.0 & $05.33 \pm 0.33$ & $52.00 \pm 1.00$ & $08.00 \pm 1.00$ & $06.00 \pm 2.00$ \\
\hline
\end{tabular}

The results are the mean \pm SE of 3 replicates, $\mathrm{LDC}=$ Leaf derived callus, $\mathrm{CDC}=$ Cotyledon derived callus, $\mathrm{HDC}=$ Hypocotyl derived callus, $\mathrm{EDC}=$ Epicotyl derived callus.

concentration of NAA $(0.1-0.5 \mathrm{mg} / \mathrm{l})$. The maximum numbers $25.00 \pm 0.58$ to $89.33 \pm 0.88 \%$ of root initiation were observed in leaf explant (Table 3). Compared to hypocotyl, epicotyl and cotyledon the frequency ranged from 10.00 \pm 0.58 to $48.33 \pm 3.38,22.00 \pm 1.15$ to $85.00 \pm 2.89$ and $20.67 \pm 2.67$ to $86.67 \pm 2.03$, 
respectively (Fig. 1E). Multiple roots were observed in in vitro regenerated shootlets on MS supplemented with $0.5 \mathrm{mg} / \mathrm{l} \mathrm{NAA}$ along with $\mathrm{GA}_{3}$ (Sharma et al. 2009).

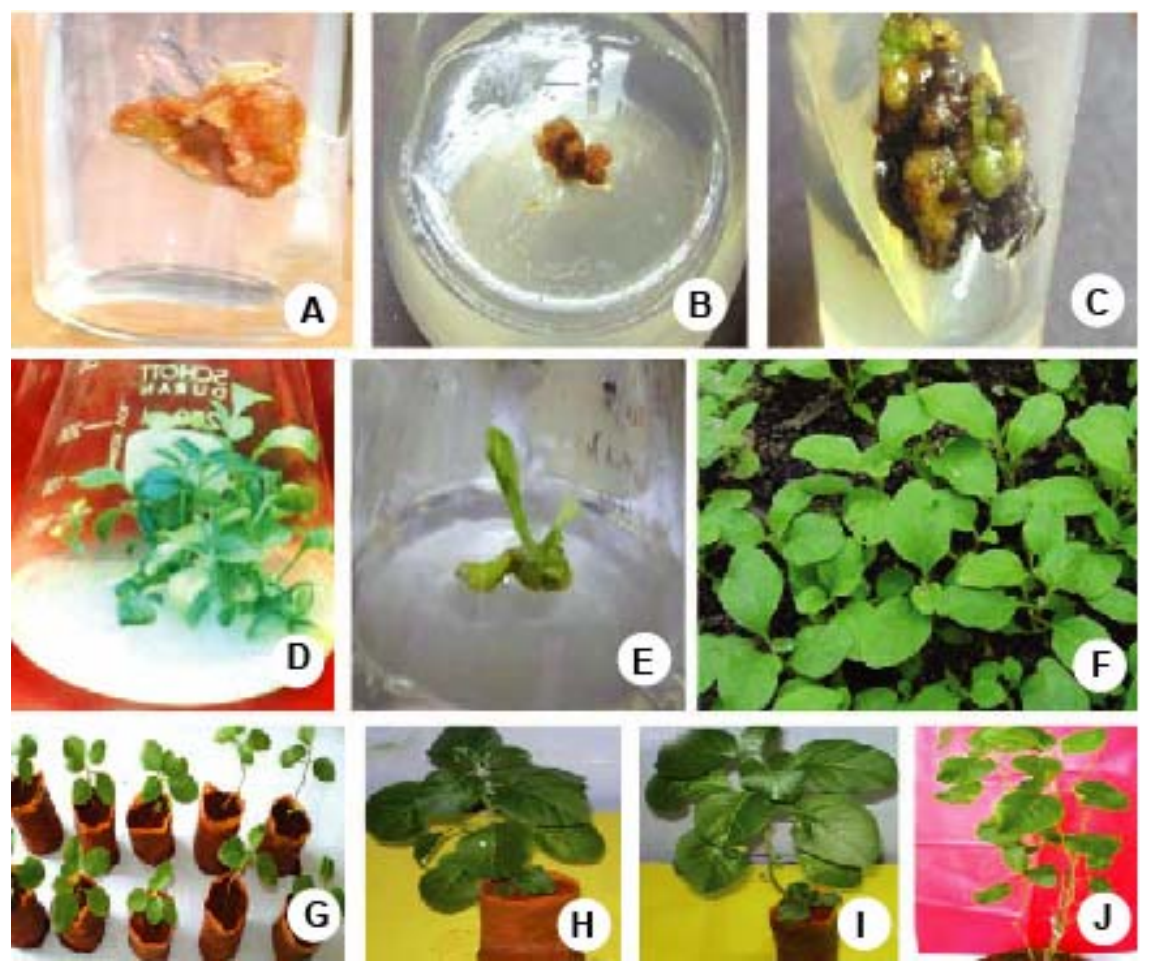

Fig. 1. Development of callus: A. Cotyledon, B. Hypocotyl, C. Leaf, D. Multiple shoot initiation, E. Shootlets produced root initiation, F. Rooted leaflets were transfered to small plastic nursery tray acclimated in the mist house for two months, G. Regenerated plantlets were transplanted with polythene bags to hardening for in vivo condition. $\mathrm{H}$ I. Well developed plants after two months and J. Same as Fig. 1I but after six months.

Regenerated plants were successfully hardened and acclimated (Fig. 1 F-J), $85 \%$ of plantlets survived well under natural conditions after transplantation. Present authors observed a quick, reliable and reproducible capacity for in vitro clonal propagation of $W$. somnifera coupled with a high morphogenetic regeneration capacity of leaf explants with multiple shoot and root formation from the callus on MS. This protocol can be used as an efficient tool for rapid multiplication, conservation and maintenance of germplasm of this important medicinal species. 
Table 3. Effect of different concentration of NAA for roots induction from four different shootlets of Withania somnifera.

\begin{tabular}{ccccc}
\hline \multirow{2}{*}{$\begin{array}{c}\text { MS }+ \text { NAA } \\
(\mathrm{mg} / \mathrm{l})\end{array}$} & \multicolumn{4}{c}{ Roots initiation $(\%)$ mean \pm SE } \\
\cline { 2 - 5 } & LDS & CDS & HDS & EDS \\
\hline 0.1 & $00.00 \pm 0.00$ & $00.00 \pm 0.00$ & $00.00 \pm 0.00$ & $00.00 \pm 0.00$ \\
0.5 & $00.00 \pm 0.00$ & $00.00 \pm 0.00$ & $22.00 \pm 1.15$ & $00.00 \pm 0.00$ \\
1.0 & $00.00 \pm 0.00$ & $10.00 \pm 0.58$ & $54.00 \pm 1.15$ & $50.00 \pm 0.58$ \\
1.5 & $25.00 \pm 0.58$ & $12.00 \pm 1.53$ & $54.00 \pm 2.00$ & $54.00 \pm 1.15$ \\
2.0 & $52.00 \pm 1.15$ & $18.00 \pm 1.15$ & $65.00 \pm 2.89$ & $70.00 \pm 1.15$ \\
3.0 & $54.00 \pm 1.15$ & $22.67 \pm 1.76$ & $70.00 \pm 2.31$ & $72.00 \pm 1.15$ \\
4.0 & $65.00 \pm 1.73$ & $47.00 \pm \mathbf{1 . 1 5}$ & $82.00 \pm 1.73$ & $75.00 \pm 1.73$ \\
5.0 & $88.00 \pm 1.15$ & $45.00 \pm 2.89$ & $\mathbf{8 5 . 0 0} \pm 2.89$ & $\mathbf{8 6 . 6 7} \pm 2.03$ \\
10.0 & $89.33 \pm \mathbf{0 . 8 8}$ & $48.33 \pm 3.38$ & $70.00 \pm 2.31$ & $85.00 \pm 2.31$ \\
20.0 & $26.00 \pm 0.58$ & $24.00 \pm 0.58$ & $26.00 \pm 1.15$ & $20.67 \pm 2.67$ \\
\hline
\end{tabular}

The results are the mean \pm SE of 3 replicates, LDS $=$ Leaf derived shootlets, CDS = Cotyledon derived shootlets, HDS = Hypocotyl derived shoot lets, EDS = Epicotyl derived shootlets.

\section{Acknowledgement}

Authors wish to thank the authority of University Grants Commission (UGC), New Delhi, for providing the fund for major research project (37-14/2009- SR).

\section{References}

Baburaj S and Gunasekaran K (1995) In vitro differentiation of shoots from leaf callus cultures of Withania somnifera (L.) Dunal. J. Ind. Bot. Soc. 74: 323-234.

Chopra NR, Chopra IP, Handa HL and Kapur LD (1958) Indigenous Drugs of India. UN Dhur and Sons, Calcutta. pp. 436-437.

Joshi C, Gajbhiye N, Phurailatpam A, Geetha KA and Maiti S (2010) Comparative morphometric, physiological and chemical studies of wild and cultivated plant types of Withania somnifera (Solanaceae). Curr. Sci. India 99 (5): 10.

Elsakka M, Grigorescu E, Stanescu U, Stanescu U and Dorneanu V (1990) New data referring to chemistry of Withania somnifera species. Rev. Med. Chir. Soc. Med. Nat. Iasi. 94: 385-387.

Kupchan SM, Doskotch RW, Bollinger P, Muphail AT, Sim GA and Saenz RJA (1965) The isolation and structure elucidation of a novel steroidal tumor inhibitor from Acnistus arborescens. J. Amer. Chem. Soc. 87: 5805.

Mishra LC, Singh BB and Dagenais S (2000) Scientific basis for the therapeutic use of Withania somnifera (Aswagaandha), a review. Altern. Med. Rev. 5: 334-346. 
Rahman M (2001) Red data Book of Vascular Plants. Bangladesh National Herbarium. Dhaka, Bangladesh.

Rani G and Grover IS (1999) In vitro callus induction and regeneration studies in Withania somnifera. Plant Cell Tiss. Org. 57: 23-27.

Roja G, Heble MR and Sipahimalani AT (1991) Tissue cultures of Withania somnifera, Morphogenesis and withanolide synthesis. Phytother. Res. 5: 185-187.

Sen J and Sharma AK (1991) Micropropagation of Withania somnifera from germinating seeds and shoots tips. Plant Cell Tiss. Org. 26: 71-73.

Siddique NA, Bari MA, Pervin MM, Nahar N, Banu LA, Paul KK, Kabir MH, Huda A KMN, Mollah MU and Ferdaus KMKB (2005) Screening of Endangered Medicinal Plants Species by Questionnaire Survey in Barind Tract in Bangladesh. Pak. J. Biol. Sci. 8 (12):1783-1793.

Sharma S, Mukesh, Chandara, Sharma and Kohli DV (2009) In vitro micropropagation of medicinally important roots and axillary bud combination. J. Optoelectron Biomed. Mater. 1(4): 379-381.

Uma Devi P, Sharada AC, Solomon FE and Kamath MS (1992) In vitro growth inhibitory effect of Withania somnifera (Ashwagandha) on a transplantable mouse tumor sarcoma 180. Ind. J. Exp. Biol. 30: 169-172.

Uma Devi P, Sharada AC and Solomon FE (1993) Anti-tumor and radiosensitizing effects of Withania somnifera (Ashwagandha) on a transplantable mouse tumor sarcoma 180. Ind. J. Exp. Biol. 31: 607-611. 